\title{
Regulation of superoxide flashes by transient and steady mitochondrial calcium elevations
}

\author{
JIAN ChongShu, HOU TingTing, YIN RongKang, CHENG HePing \& WANG XianHua* \\ State Key Laboratory of Biomembrane and Membrane Biotechnology, Beijing Key Laboratory of Cardiometabolic Molecular Medicine, \\ Institute of Molecular Medicine, Peking-Tsinghua Center for Life Sciences, Peking University, Beijing 100871, China
}

Received September 3, 2013; accepted September 18, 2013; published online April 2, 2014

\begin{abstract}
The mitochondria play essential roles in both intracellular calcium and reactive oxygen species signaling. As a newly discovered universal and fundamental mitochondrial phenomenon, superoxide flashes reflect transient bursts of superoxide production in the matrix of single mitochondria. Whether and how the superoxide flash activity is regulated by mitochondrial calcium remain largely unknown. Here we demonstrate that elevating mitochondrial calcium either by the calcium ionophore ionomycin or by increasing the bathing calcium in permeabilized HeLa cells increases superoxide flash incidence, and inhibition of the mitochondrial calcium uniporter activity abolishes the flash response. Quantitatively, the superoxide flash incidence is correlated to the steady-state mitochondrial calcium elevation with 1.7 -fold increase per $1.0 \Delta F / F_{0}$ of Rhod-2 signal. In contrast, large mitochondrial calcium transients (e.g., peak $\triangle F / F_{0} \sim 2.8$, duration $\sim 2 \mathrm{~min}$ ) in the absence of steady-state elevations failed to alter the flash activity. These results indicate that physiological levels of sustained, but not transient, mitochondrial calcium elevation acts as a potent regulator of superoxide flashes, but its mechanism of action likely involves a multi-step, slow-onset process.
\end{abstract}

superoxide flash, calcium signaling, reactive oxygen species (ROS), mitochondrion

Citation: Jian CS, Hou TT, Yin RK, Cheng HP, Wang XH. Regulation of superoxide flashes by transient and steady mitochondrial calcium elevations. Sci China Life Sci, 2014, 57: 495-501, doi: 10.1007/s11427-014-4628-z

Calcium $\left(\mathrm{Ca}^{2+}\right)$ and reactive oxygen species (ROS) are important intracellular signaling molecules. The mitochondria play pivotal roles in both $\mathrm{Ca}^{2+}$ handling and redox homeostasis. It also provides a stage for $\mathrm{Ca}^{2+}$ and ROS to tango on. $\mathrm{Ca}^{2+}$ modulates ROS homeostasis by regulating the ROS-generating and antioxidant systems, while ROS modify the components of the $\mathrm{Ca}^{2+}$ signaling toolkit and reshape local and global $\mathrm{Ca}^{2+}$ signal amplitudes and kinetics [1].

With the aid of a novel, reversible superoxide biosensor, mt-cpYFP, we recently discovered stochastic, discrete and transient superoxide production events, named superoxide flashes, in single mitochondria [2]. As a novel ROSgenerating activity, superoxide flash exists in isolated single

*Corresponding author (email: xianhua@pku.edu.cn) mitochondria, cultured cells, ex vivo beating hearts and even living animals [2-4]. A superoxide flash event is initiated with transient opening of putative mitochondrial permeability transition pore (mPTP) and requires an intact mitochondrial electron transport chain (ETC) [2]. Functionally, superoxide flashes participate in the regulation of metabolism, cell proliferation and differentiation, hyperosmotic, inflammatory and oxidative stress responses, and even in the process of aging [5-10].

Whether and how is superoxide flash activity intertwined with mitochondrial $\mathrm{Ca}^{2+}$ signaling? Wang et al. [2] explored the relationship between $\mathrm{Ca}^{2+}$ and superoxide flash in cardiac cells and found that superoxide flash frequency is unaltered by either a 2-fold increase or an abolition of $\mathrm{Ca}^{2+}$ sparks. Hou et al. [5] found that elevating $\mathrm{Ca}^{2+}$ or ROS 
production alone was inefficacious in triggering superoxide flash in HeLa cells. But when the two components act together, a flurry of flashes occur due to synergistic effect. However, the exact regulatory mechanism of $\mathrm{Ca}^{2+}$ on superoxide flash production remains incompletely understood. Given that extreme mitochondrial $\mathrm{Ca}^{2+}$ elevation, verging on apoptosis, suffices to trigger irreversible mPTP openings [11], it is also of interest to delineate the mode with which $\mathrm{Ca}^{2+}$ regulates transient mPTP openings as reflected by discrete superoxide flashes. In this study, we used several ways to selectively manipulate intracellular $\mathrm{Ca}^{2+}$ and found that superoxide flash frequency is tightly correlated with the steady mitochondrial $\mathrm{Ca}^{2+}$ level but appears to be insensitive to transient mitochondrial $\mathrm{Ca}^{2+}$ elevations (duration $\sim 2$ min). These results indicate that mitochondrial $\mathrm{Ca}^{2+}$ is a potent regulator of superoxide flashes, but its mechanism of action likely involves a multi-step, slow-onset process.

\section{Materials and methods}

\subsection{Reagents}

Cyclosporine A, saponin, ionomycin and ruthenium red were from Sigma, USA. Rhod-2 AM, Fluo-4 AM, Lipofectamine RNAiMax, Dulbecco's modified Eagle's medium (DMEM), penicillin and streptomycin were from Invitrogen, USA. Fetal bovine serum (FBS) was from Hyclone, USA.

\subsection{Cell culture and RNA interference assay}

The HeLa cells stably expressing mitochondria-targeted cpYFP (mt-cpYFP) were established as previously [8]. Cells were grown in DMEM medium supplemented with $10 \% \mathrm{FBS}$ and $1 \%$ penicillin and streptomycin at $37^{\circ} \mathrm{C}$ under $5 \% \mathrm{CO}_{2}$. For RNA interference of human MCU (CCDC109a), two double-stranded small RNAs and a negative control (NC) RNA were used as follows: MCU-1 sense: CCAGCAACUAUACACCACACUdTdT; MCU-1 antisense: AGUGUGGUGUAUAGUUGCUGGdTdT; MCU-2 sense: GCAAGGAGUUUCUUUCUCUUUdTdT; MCU-2 antisense: AAAGAGAAAGAAACUCCUUGCdTdT; NC sense: UUCUCCGAACGUGUCACGUdTdT; NC antisense: ACGUGACACGUUCGGAGAAdTdT.

For transfection, $100 \mathrm{nmol} \mathrm{L}{ }^{-1}$ siRNA was transiently transfected into the mt-cpYFP-expressing HeLa cells with Lipofectamine RNAiMax according to the manufacturer's instructions. Confocal imaging and Western blotting were performed 60-72 $\mathrm{h}$ after transfection.

\section{$1.3 \mathrm{Ca}^{2+}$ measurement}

Fluo-4 AM and Rhod-2 AM were used to measure the cytosolic and mitochondrial $\mathrm{Ca}^{2+}$ signal respectively according to the manufacturer's instructions. Briefly, HeLa cells were loaded with Fluo-4 AM $\left(5 \mu \mathrm{mol} \mathrm{L} \mathrm{L}^{-1}\right)$ or Rhod-2 AM (5

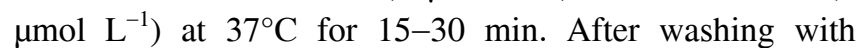
Tyrode's solution consisting (in mmol L ${ }^{-1}$ ) $137 \mathrm{NaCl}, 5.4$ $\mathrm{KCl}, 1.2 \mathrm{MgCl}_{2}, 1.2 \mathrm{NaH}_{2} \mathrm{PO}_{4}, 10 \mathrm{D}$-glucose, and 20 HEPES ( $\mathrm{pH} 7.35$, adjusted with $\mathrm{NaOH}$ ), the Fluo-4 and Rhod-2 signals were monitored on an inverted Zeiss LSM 710 confocal microscope equipped with a $40 \times, 1.3 \mathrm{NA}$ oil-immersion objective. For Fluo-4 fluorescence, images were acquired by exciting at $488 \mathrm{~nm}$ and collecting the emission at 505-530 nm. For Rhod-2 fluorescence, images were taken by exciting at $543 \mathrm{~nm}$ and collecting the emission at $>560 \mathrm{~nm}$. Usually, 450 frames of $512 \times 512$ pixels were collected at $2 \mathrm{~s} /$ frame in bidirectional scanning mode.

\subsection{Cell permeabilization}

The cells were permeabilized with saponin treatment. Briefly, cells were washed in $\mathrm{Ca}^{2+}$-free Tyrode's solution for five times to remove intracellular $\mathrm{Ca}^{2+}$ before permeabilization and then permeabilized with $50 \mu \mathrm{g} \mathrm{mL} \mathrm{m}^{-1}$ saponin in the intracellular solution (in mmol L ${ }^{-1}, 100 \mathrm{KOH}, 100$ aspartic acid, $20 \mathrm{KCl}, 0.81 \mathrm{MgCl}_{2}, 3 \mathrm{Mg}$-ATP, 0.5 EGTA, 5 phosphocreatine $\cdot$ ditris, 10 phosphocreatine $\cdot \mathrm{Na}, 5$ creatine phosphokinase, 10 glutathione, $8 \%$ dextran and 20 HEPES (pH 7.2, adjusted with $\mathrm{KOH}$ )) for $30 \mathrm{~s}$. After permeabilization, cells were bathed in intracellular solution without saponin for further experiments.

\subsection{Imaging and analysis of superoxide flashes}

A Zeiss LSM 710 inverted confocal microscope with a 40×, 1.3 NA oil-immersion objective was used for detecting superoxide flashes. Mt-cpYFP was excited at 488 and $405 \mathrm{~nm}$, and the emission was collected at $505-530 \mathrm{~nm}$. The axial resolution was set to $2.0 \mu \mathrm{m}$ and the size of the imaging region was $70.71 \mu \mathrm{m} \times 70.71 \mu \mathrm{m}$. In a typical time series recording, 100 frames of $512 \times 512$ pixels were collected at $1 \mathrm{~s} /$ frame in bidirectional scanning mode. Images were usually acquired within $40 \mathrm{~min}$ after different treatments. All experiments were performed at room temperature $\left(24-26^{\circ} \mathrm{C}\right)$ unless specified otherwise.

Superoxide flashes were analyzed using customdeveloped programs written in Interactive Data Language (IDL, Research Systems) as described previously [12]. Individual superoxide flashes were identified with the aid of custom-devised computer algorithms, and their morphological and kinetic properties were measured automatically.

\subsection{Statistics}

Data are expressed as mean \pm SEM. Student's $t$-test was applied to determine the statistical significance. $P<0.05$ was considered statistically significant. 


\section{Results}

\subsection{Superoxide flash incidence positively correlated with intracellular steady-state $\mathrm{Ca}^{2+}$ level}

First, we sought to determine whether $\mathrm{Ca}^{2+}$ transient elicited by $\mathrm{Ca}^{2+}$ ionophore ionomycin is able to activate superoxide flashes. When cells were perfused with Tyrode's solution containing $1.8 \mathrm{mmol} \mathrm{L}^{-1} \mathrm{Ca}^{2+}$, application of ionomycin (1 $\mu \mathrm{mol} \mathrm{\textrm {L } ^ { - 1 }}$ ) immediately elicited robust cytosolic and mitochondrial $\mathrm{Ca}^{2+}$ transients that displayed a 7.5- and 3.8-fold peak increase of Fluo-4 and Rhod-2 fluorescence, respectively. Then cytosolic and mitochondrial $\mathrm{Ca}^{2+}$ gradually declined toward an elevated steady level (Fluo-4: $F / F_{0}=$ $1.31 \pm 0.03$; Rhod-2: $F / F_{0}=1.30 \pm 0.02, n=61-70$ cells) (Figure $1 \mathrm{~A})$. Ionomycin was equally efficient in eliciting $\mathrm{Ca}^{2+}$ transients in cells perfused with higher extracellular $\mathrm{Ca}^{2+}$ $\left(\left[\mathrm{Ca}^{2+}\right]_{\mathrm{ex}}=3.6,5\right.$ and $10 \mathrm{mmol} \mathrm{L}^{-1}$ ) (Figure 1B-D). Interestingly, the steady $\mathrm{Ca}^{2+}$ level after ionomycin stimulation increased dose-dependently with the extracellular $\mathrm{Ca}^{2+}$ concentration (Fluo-4: $F / F_{0}=2.02 \pm 0.06,3.03 \pm 0.10$ and $2.88 \pm$ 0.08 ; Rhod-2: $F / F_{0}=1.62 \pm 0.04,2.59 \pm 0.0$ and $2.70 \pm 0.07$; at $3.6,5$ and $10 \mathrm{mmol} \mathrm{L}^{-1}\left[\mathrm{Ca}^{2+}\right]_{\mathrm{ex}}$ respectively, $n=61-70$ cells) (Figure 1F), while the peak amplitudes remained unaffected
(Fluo-4: $\quad F / F_{0}=7.75 \pm 0.20, \quad 8.18 \pm 0.19,6.63 \pm 0.16 ;$ Rhod $-2: F / F_{0}=4.42 \pm 0.12,5.31 \pm 0.12,4.11 \pm 0.11$ at $3.6,5$ and $10 \mathrm{mmol} \mathrm{L}{ }^{-1}\left[\mathrm{Ca}^{2+}\right]_{\text {ex }}$ respectively, $n=61-70$ cells) (Figure 1E). One possible explanation is that the $\mathrm{Ca}^{2+}$ peak reflects the $\mathrm{Ca}^{2+}$ store capacity of the endoplasmic reticulum (ER), while the steady-state $\mathrm{Ca}^{2+}$ level is the result of $\mathrm{Ca}^{2+}$ ionophone ionomycin equilibrating the extra- and intracellular $\mathrm{Ca}^{2+}$.

Parallel experiments were performed to measure the superoxide flash response. At $\left[\mathrm{Ca}^{2+}\right]_{\mathrm{ex}}$ of $3.6 \mathrm{mmol} \mathrm{L}{ }^{-1}$, superoxide flash incidence was slightly but significantly increased after ionomycin stimulation compared with ionomycin treatment at $1.8 \mathrm{mmol} \mathrm{L}^{-1}\left[\mathrm{Ca}^{2+}\right]_{\mathrm{ex}}$. With further increase of $\left[\mathrm{Ca}^{2+}\right]_{\mathrm{ex}}$, the flash incidence reached $1.45 \pm 0.15$ and $2.03 \pm 0.29$ events $/ 100 \mathrm{~s} /$ cell in groups at 5 and $10 \mathrm{mmol}$ $\mathrm{L}^{-1}\left[\mathrm{Ca}^{2+}\right]_{\mathrm{ex}}$, which was 1.2- and 2.1-fold greater than that in control cells $(0.65 \pm 0.10$ flashes/100 s/cell) (Figure 2A). Moreover, linear regression showed a trend of positive correlation between the superoxide flash incidence and the steady level of mitochondrial $\mathrm{Ca}^{2+}\left(R^{2}=0.82, \quad r=0.91\right.$, $P=0.092$ ) (Figure $2 \mathrm{~B}$ ), revealing a high sensitivity of superoxide flashes to the steady-state mitochondrial $\mathrm{Ca}^{2+}$ elevation.
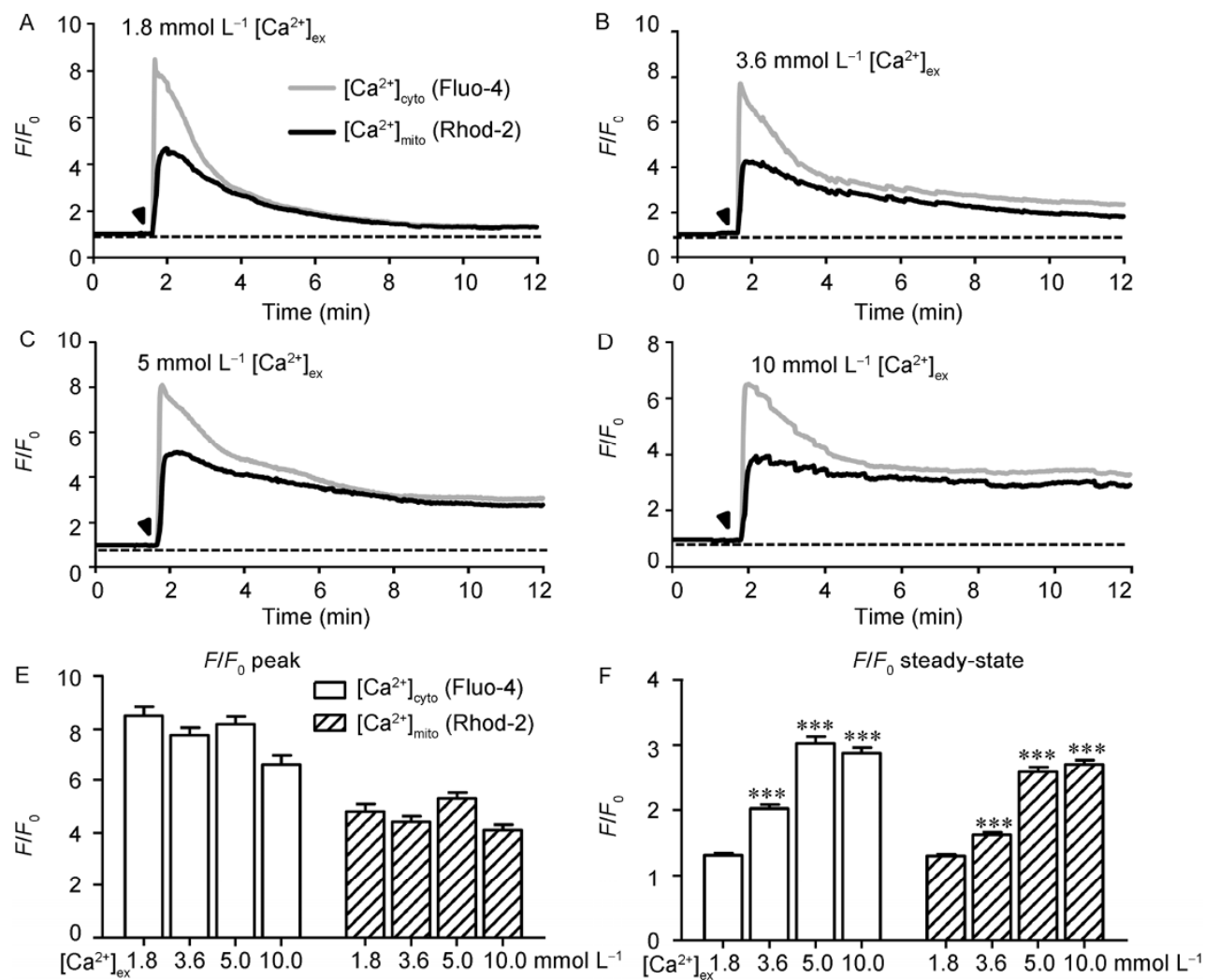

Figure 1 Cytosolic and mitochondrial $\mathrm{Ca}^{2+}$ transients induced by ionomycin. A-D, Response of cytosolic and mitochondrial $\mathrm{Ca}^{2+}$ measured with Fluo-4 and Rhod-2 respectively upon ionomycin $\left(1 \mu \mathrm{mol} \mathrm{L}{ }^{-1}\right)$ treatment in the presence of $1.8(\mathrm{~A}), 3.6(\mathrm{~B}), 5(\mathrm{C})$ and $10(\mathrm{D}) \mathrm{mmol} \mathrm{L}^{-1} \mathrm{extracellular} \mathrm{Ca}^{2+}\left(\left[\mathrm{Ca}^{2+}\right]_{\mathrm{ex}}\right)$. Arrowheads indicate the time of adding ionomycin. E, Averaged peak value of the cytosolic and mitochondrial $\mathrm{Ca}^{2+}$ transients. Note that there are no significant difference with altering $\left[\mathrm{Ca}^{2+}\right]_{\mathrm{ex}} . \mathrm{F}$, Cytosolic and mitochondrial steady state $\mathrm{Ca}^{2+}$ level after ionomycin treatment with varying $\left[\mathrm{Ca}{ }^{2+}\right]_{\mathrm{ex}}$. Data are expressed as the mean \pm SEM. $n=61-70$ cells per group. $* * *, P<0.001$ vs. $1.8 \mathrm{mmol} \mathrm{L}^{-1}\left[\mathrm{Ca}^{2+}\right]_{\mathrm{ex}}$ group. 

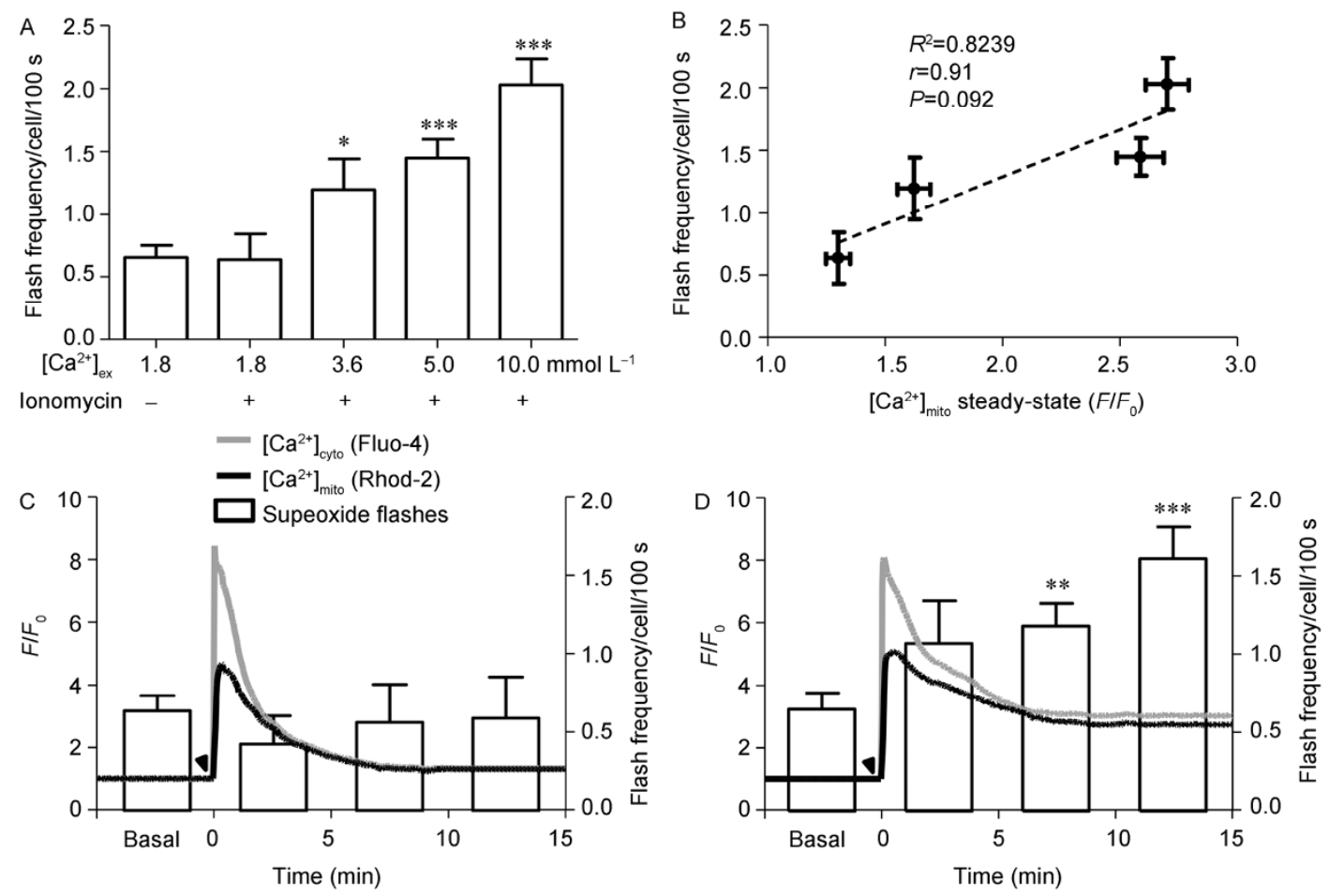

Figure 2 Induction of superoxide flashes by steady-state $\mathrm{Ca}^{2+}$ elevation. A, Superoxide flash frequency after ionomycin treatment in the presence of varying $\left[\mathrm{Ca}^{2+}\right]_{\mathrm{ex}}$. Data are expressed as the mean \pm SEM. $n=51-98$ cells per group. *, $P<0.05 ; * *, P<0.01$; ***, $P<0.001$ vs. $1.8 \mathrm{mmol} \mathrm{L}^{-1}\left[\mathrm{Ca}^{2+}\right]_{\mathrm{ex}}$ without ionomycin treatment group. B, Trend of positive correlation between steady-state mitochondrial $\mathrm{Ca}^{2+}$ level and superoxide flash incidence. Dashed line shows the

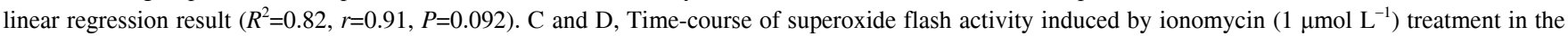
presence of $1.8(\mathrm{C})$ and 5 (D) $\mathrm{mmol} \mathrm{L}^{-1}\left[\mathrm{Ca}^{2+}\right]_{\mathrm{ex}}$. The gray and black traces show cytosolic and mitochondrial $\mathrm{Ca}^{2+}$ transients respectively. Arrowheads indicate the time of adding ionomycin. Data are expressed as mean \pm SEM. $n=14-84$ cells per group. **, $P<0.01 ; * * *, P<0.001$ vs. basal group.

Time-course analysis revealed that the aforementioned strong transient $\mathrm{Ca}^{2+}$ elevation within the first 5 min was ineffective in augmenting superoxide flash frequency when cells were perfused with $1.8 \mathrm{mmol} \mathrm{L}^{-1}\left[\mathrm{Ca}^{2+}\right]_{\mathrm{ex}}$ (Figure $2 \mathrm{C}$ ), in agreement with Hou et al. [5]. In the presence of $5 \mathrm{mmol} \mathrm{L}^{-1}$ $\left[\mathrm{Ca}^{2+}\right]_{\mathrm{ex}}$, superoxide flash activity was activated gradually, displaying a significant increase only after $5 \mathrm{~min}$ of ionomycin addition when mitochondrial and cytosolic $\mathrm{Ca}^{2+}$ levels were at plateau, while a prominent early cytosolic and mitochondrial $\mathrm{Ca}^{2+}$ peak occurred at 48 and $72 \mathrm{~s}$ (Figure 2D). These results indicate that steady-state rather than transient elevation of intracellular $\mathrm{Ca}^{2+}$ induces superoxide flashes.

\subsection{Activation of superoxide flashes in permeabilized cells by increasing bathing $\mathrm{Ca}^{2+}$}

To further elucidate the regulation of superoxide flash by sustained $\mathrm{Ca}^{2+}$ elevation, we directly manipulated the cytosolic $\mathrm{Ca}^{2+}\left(\left[\mathrm{Ca}^{2+}\right]_{\mathrm{c}}\right)$ by permeabilizing cells with saponin (1 $\mu \mathrm{g} \mathrm{mL}^{-1}$ ) and then bathing the cells in intracellular solution with varying $\mathrm{Ca}^{2+}$ concentrations $(0.1,0.3,0.5,1,3$ and 10 $\left.\mu \mathrm{mol} \mathrm{L}{ }^{-1}\right)$. Consistent with aforementioned strong dependence of superoxide flash on steady $\mathrm{Ca}^{2+}$ level, superoxide flashes responded to $\left[\mathrm{Ca}^{2+}\right]_{c}$ manipulations in a dose- dependent manner. Flurries of superoxide flash activity were visualized upon challenge with $\left[\mathrm{Ca}^{2+}\right]_{\mathrm{c}}$ greater than 1 $\mu \mathrm{mol} \mathrm{L} \mathrm{L}^{-1}$, displaying 2.2-, 2.7- and 3-fold increase at 1,3 and $10 \mu \mathrm{mol} \mathrm{L}{ }^{-1}\left[\mathrm{Ca}^{2+}\right]_{c}$, respectively (Figure $3 \mathrm{~A}$ ).

Mitochondrial targeting cpYFP also enabled us to monitor mitochondrial morphology changes. We noticed that the flash response at supra-micromolar $\left[\mathrm{Ca}^{2+}\right]_{\mathrm{c}}$ was accompanied by mitochondrial fragmentation and swelling (Figure 3C), typical features of mPTP opening. Pretreating cells with cyclosporine A (CsA, $\left.1 \mu \mathrm{mol} \mathrm{L}{ }^{-1}\right)$, which inhibits the mPTP opening by targeting to cyclophilin D [13], blocked the morphological change together with $\mathrm{Ca}^{2+}$-induced flashes (Figure 3B and C). These data substantiate the notion that superoxide flashes in permeabilized cells are likely triggered by transient and reversible opening of mPTP.

\subsection{Roles of mitochondrial $\mathrm{Ca}^{2+}$ uniport in activation of superoxide flashes by $\mathrm{Ca}^{2+}$}

To determine whether cytosolic or mitochondrial $\mathrm{Ca}^{2+}$ is responsible for activating superoxide flashes, we investigated the effect of inhibiting the mitochondrial $\mathrm{Ca}^{2+}$ transport. By taking advantage of the recent molecular identification of MCU [14,15], the channel pore element of mitochondrial $\mathrm{Ca}^{2+}$ uniporter, we showed that siRNA knock- 

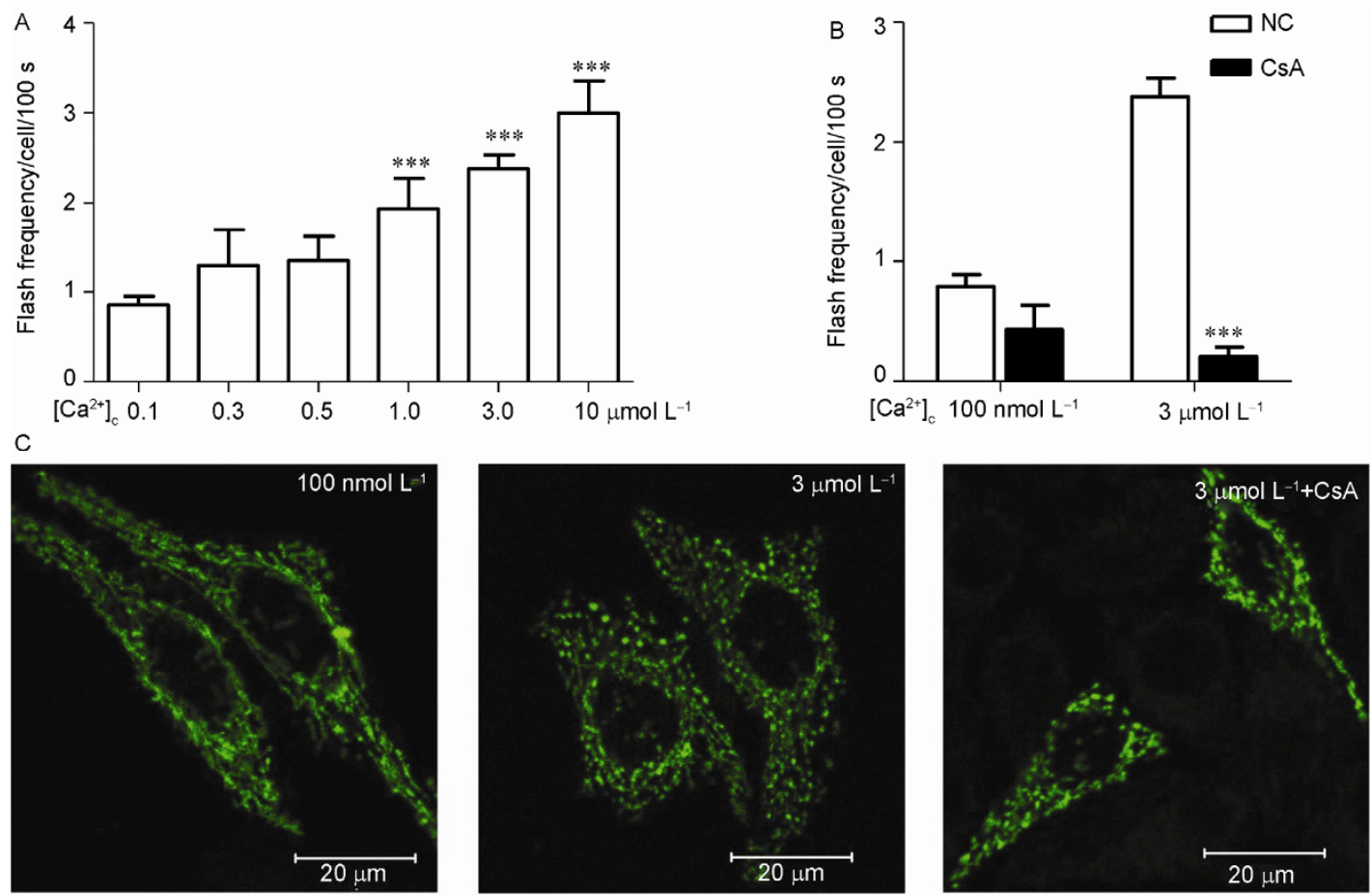

Figure 3 Increasing bathing $\mathrm{Ca}^{2+}$ in permeabilized cells augments superoxide flash incidence. A, Superoxide flash incidence in permeabilized HeLa cells with altering cytosolic $\mathrm{Ca}^{2+}\left(\left[\mathrm{Ca}^{2+}\right]_{\mathrm{c}}\right)$. The data are expressed as the mean \pm SEM. $n=17-195$ cells per group. ${ }^{* * *}, P<0.001$ vs. $0.1 \mu \mathrm{mol} \mathrm{L}{ }^{-1}\left[\mathrm{Ca}^{2+}\right]_{\mathrm{c}}$ group. B, Inhibition of superoxide flashes by cyclosporine A (CsA, $2 \mu \mathrm{mol} \mathrm{L}^{-1}$ ). The data are expressed as the mean \pm SEM. $n=14-195$ cells per group. $* * *, P<0.001$ vs. negative control (NC). C, Representative confocal images of mitochondrial morphology under 0.1 and $3 \mu \mathrm{mol} \mathrm{L} \mathrm{L}^{-1}\left[\mathrm{Ca}^{2+}\right]_{c}$ with or without CsA treatment.

down of MCU with two independent double-strand small RNAs (siMCU-1 and siMCU-2) decreased MCU protein expression (Figure 4A). As a result, transient mitochondrial $\mathrm{Ca}^{2+}$ elevation responding to ionomycin was significantly decreased but transient cytosolic $\mathrm{Ca}^{2+}$ elevation and the steady cytosolic and mitochondrial $\mathrm{Ca}^{2+}$ levels remained unchanged (Figure 4B and C). Concomitantly, superoxide flashes induced by ionomycin under $5 \mathrm{mmol} \mathrm{L}^{-1}\left[\mathrm{Ca}^{2+}\right]_{\mathrm{ex}}$ was not affected upon MCU knockdown (Figure 4D), consistent with the idea that steady-state but not transient $\mathrm{Ca}^{2+}$ elevation activates superoxide flashes.

Since ionomycin permits $\mathrm{Ca}^{2+}$ entry into the mitochondria independent of mitochondrial $\mathrm{Ca}^{2+}$ uniport, this explains the insensitivity of mitochondrial steady-state $\mathrm{Ca}^{2+}$ and superoxide flash to knockdown of MCU. However, in permeabilized cells in the absence of ionomycin, MCU provides the major route to couple cytosolic $\mathrm{Ca}^{2+}$ with mitochondrial matrix $\mathrm{Ca}^{2+}$ elevation. Inhibition of MCU activity by ruthenium red (RR, $\left.500 \mathrm{nmol} \mathrm{L}^{-1}\right)$, a blocker of MCU, or by genetic disruption with siRNAs both significantly depressed superoxide flashes induced by micromolar $\left[\mathrm{Ca}^{2+}\right]_{\mathrm{c}}$ in permeabilized cells (Figure 5). Specifically, RR decreased flash frequency by $73.8 \%$, siMCU-1 by $73.2 \%$ and siMCU-2 by $49.1 \%$. These results showed that superoxide flashes are activated by the steady-state mitochondrial $\mathrm{Ca}^{2+}$ elevation, but not the cytosolic one.

\section{Discussion}

Superoxide flashes represent quantal bursts of superoxide production in single mitochondria. The present study aims to determine how this newly discovered, dynamic, fundamental, physiological mitochondrial activity is regulated by the prominent $\mathrm{Ca}^{2+}$ signaling. We have demonstrated that elevating mitochondrial steady $\mathrm{Ca}^{2+}$ level either by ionomycin (in intact cells) or by increasing the bathing $\mathrm{Ca}^{2+}$ (in saponin-permeabilized cells) effectively augmented the superoxide flash incidence. Surprisingly, we found that transient mitochondrial $\mathrm{Ca}^{2+}$ elevation, even when the mitochondrial $\mathrm{Ca}^{2+}$ level reached several $\mu \mathrm{mol} \mathrm{L}{ }^{-1}$ within the first 5 min after ionomycin addition (Rhod-2 peak: $\Delta F / F_{0}$ $\sim 3, K_{d}=570 \mathrm{nmol} \mathrm{L}^{-1}$ ), failed to stimulate any detectable increase in superoxide flash activity. In sharp contrast, a small fractional increase of mitochondrial steady-state $\mathrm{Ca}^{2+}$ greatly enhanced the superoxide flash activity (1.7-fold increase in flash incidence per $1.0 \Delta F / F_{0}$ of Rhod-2 fluorescence). Linear regression showed a trend of positive correlation between the flash activity and the steady-state mitochondrial $\mathrm{Ca}^{2+}$ level, suggesting that the apparent $\mathrm{Ca}^{2+}$ affinity for the regulation of flashes is in the same range with $K_{d}$ of Rhod-2. These results show an important feature for $\mathrm{Ca}^{2+}$ regulation of superoxide flashes in HeLa cells: steady mitochondrial $\mathrm{Ca}^{2+}$ is a powerful and potent regulator of superoxide flashes, but the transient mitochondrial $\mathrm{Ca}^{2+}$ 

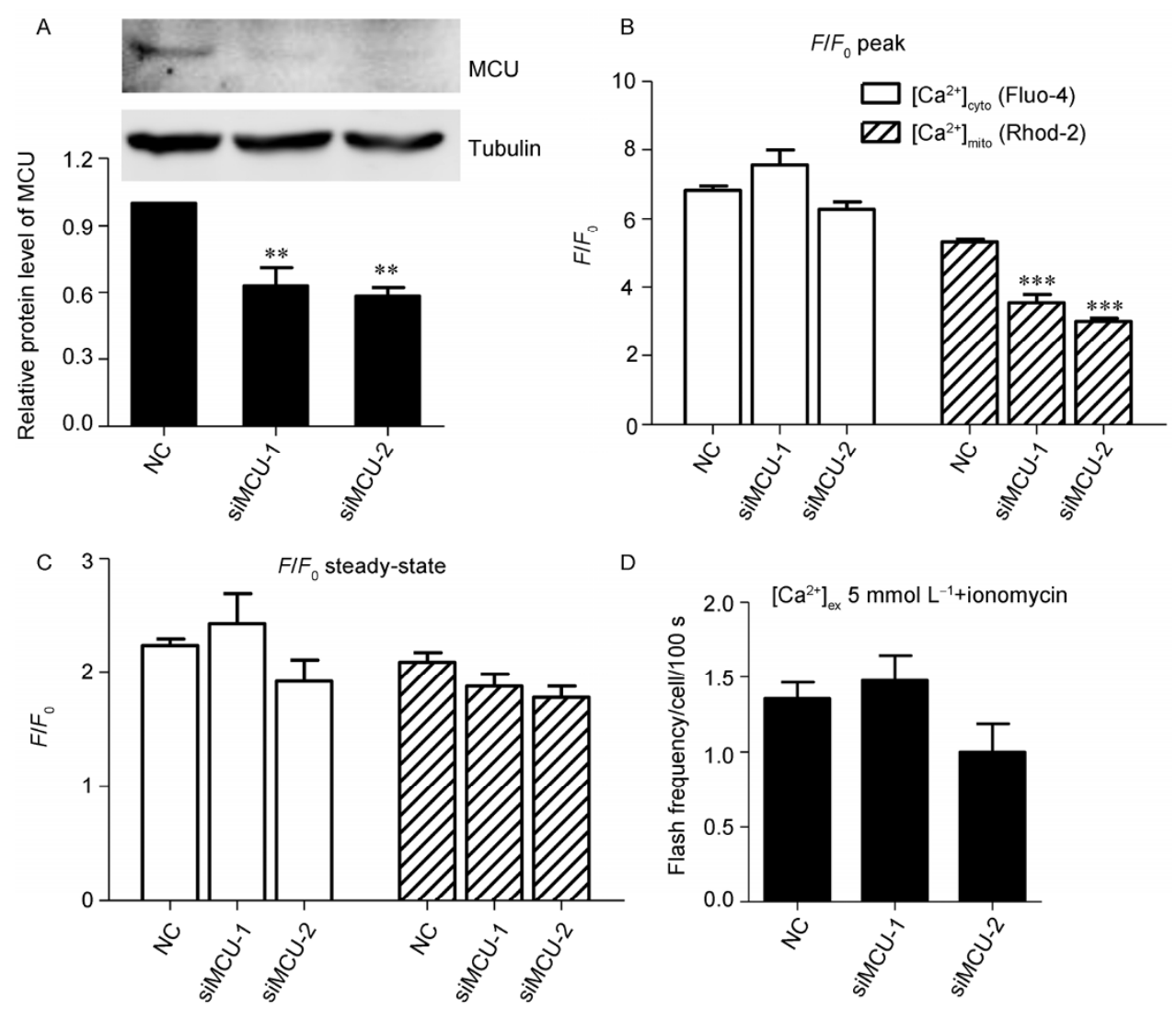

Figure $4 \mathrm{MCU}$ is dispensable for ionomycin induced superoxide flashes in intact cells. A, Western-blot assessing the knockdown efficiency of MCU. Two double-strand siRNAs (siRNA-1, siRNA-2) and one negative control RNA (NC) were used. Data are expressed mean \pm SEM, $n=3$ experiments. $* *, P<0.01$ vs. NC. B and C, MCU knockdown decreased the peak of cytosolic and mitochondrial $\mathrm{Ca}^{2+}$ transient (B), but showed little effect on the steady Ca ${ }^{2+}$ level (C). The data are expressed as the mean \pm SEM. $n=37-76$ cells per group. D, Effect of MCU knockdown on superoxide flash frequency induced by ionomycin in the presence of $5 \mathrm{mmol} \mathrm{L}{ }^{-1}\left[\mathrm{Ca}^{2+}\right]_{\mathrm{ex}}$. The data are expressed as the mean \pm SEM. $n=49-177$ cells per group. $* * *, P<0.001$ vs. NC.
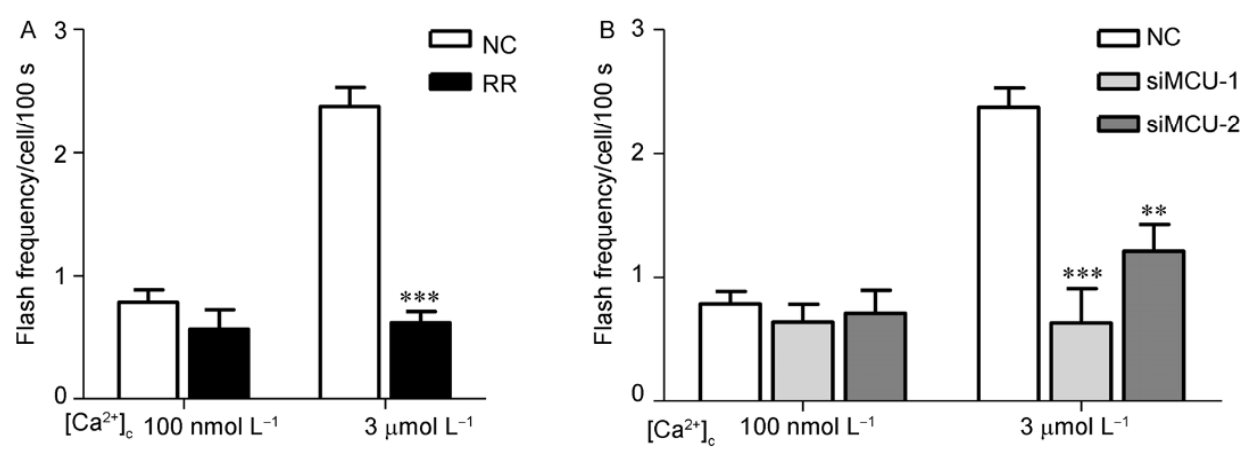

Figure 5 Requirement of MCU for superoxide flashes induced by high cytosolic $\mathrm{Ca}^{2+}$ in permeabilized cells. Inhibition of MCU with ruthenium red (RR, $500 \mathrm{nmol} \mathrm{L}{ }^{-1}$ ) (A) or by RNAi (B) both depressed superoxide flash incidence in permeabilized cells. The data are expressed as the mean \pm SEM. $n=28-195$ cells per group. $* *, P<0.01 ; * * *, P<0.001$ vs. NC.

signal is not. It can be inferred that the $\mathrm{Ca}^{2+}$-dependent regulatory mechanism likely involves a multi-step, slow-onset, but high-affinity process.

Blockage of mitochondrial $\mathrm{Ca}^{2+}$ uniport in permeabilized cells significantly decreased the hyperactive superoxide flashes induced by micromolar cytosolic $\mathrm{Ca}^{2+}$, indicating that it is the high steady $\mathrm{Ca}^{2+}$ level within mitochondria, but not cytosol, that activates superoxide flashes. Interestingly, the peak of transient mitochondrial $\mathrm{Ca}^{2+}$ induced by ionomycin is MCU-dependent, while the steady-state mitochondrial $\mathrm{Ca}^{2+}$ level and superoxide flash frequency are not. This further emphasizes the close relationship between superoxide flash and steady mitochondrial $\mathrm{Ca}^{2+}$ level.

Possible mechanism of superoxide flashes induced by elevated steady-state mitochondrial $\mathrm{Ca}^{2+}$ might be (i) increase of ROS originating from ETC accelerated by steady- 
state mitochondrial $\mathrm{Ca}^{2+}$ elevation. Mitochondrial $\mathrm{Ca}^{2+}$ is a potent regulator of tricarboxylic acid (TCA) cycle and oxidative phosphorylation. It activates three dehydrogenases from TCA cycle, pyruvate dehydrogenase, isocitrate dehydrogenase and $\alpha$-ketoglutarate dehydrogenase, thus increases the reaction rate of many steps in the cycle [16]. Adenine nucleotide translocator (ANT) and ATP synthase have also been reported to be activated by mitochondrial $\mathrm{Ca}^{2+}[17,18]$. Hence, mitochondrial $\mathrm{Ca}^{2+}$ might increase ROS production by enhancing mitochondrial respiration through the socalled parallel activation mechanism. As a result, mitochondrial $\mathrm{Ca}^{2+}$ and basal ROS elevation synergistically trigger superoxide flashes [5]. (ii) Involvement of $\mathrm{Ca}^{2+}$ downstream signaling cascades that regulate flash activity. Slow response of superoxide flashes to mitochondrial $\mathrm{Ca}^{2+}$ elevation suggests that, rather than being a direct trigger, mitochondrial $\mathrm{Ca}^{2+}$ might have evoked cumulative activation of some enzymes such as protein kinase $\mathrm{C}$ (PKC) and calmodulin-dependent protein kinase II (CaMK II), resulting in phosphorylation of downstream proteins. In this regard, whether CaMK II, PKC or other $\mathrm{Ca}^{2+}$ regulated enzymes are present within mitochondria, and if so, how they regulate superoxide flashes warrant further investigation.

In summary, steady-state elevation of mitochondrial $\mathrm{Ca}^{2+}$ dose-dependently augments flash activity, while transient elevation alone fails to induce any detectable flash response. The mechanism of action likely involves a multi-step, slow-onset process. It should also be appreciated that $\mathrm{Ca}^{2+}$ dependent regulation of transient mPTP opening (reflected by the flash incidence) operates at physiological $\mathrm{Ca}^{2+}$ range whereas irreversible mPTP opening (as seen in cells committing to apoptosis) requires much higher mitochondrial $\mathrm{Ca}^{2+}$ elevations. Nevertheless, both transient and irreversible mPTP activities can be activated by $\mathrm{Ca}^{2+}$ or ROS acting alone $[11,19,20]$ (and this study) and, more importantly, share the property that $\mathrm{Ca}^{2+}$ and ROS act as powerful synergistic regulators $[5,20]$. It is thus tempting to speculate that the same or similar core mechanism, operating in distinctly different modes, may underlie the flash genesis and the irreversible mitochondrial permeability transition.

This work was supported by the National Key Basic Research Program of China (2011CB809100, 2013CB531200) and the National Natural Science Foundation of China (31221002, 31130067, 31123004, 30900264).

1 Yan Y, Wei CL, Zhang WR, Cheng HP, Liu J. Cross-talk between calcium and reactive oxygen species signaling. Acta Pharmacol Sin, 2006, 27: 821-826

2 Wang W, Fang H, Groom L, Cheng A, Zhang W, Liu J, Wang X, Li K, Han P, Zheng M, Yin J, Wang W, Mattson MP, Kao JP, Lakatta EG, Sheu SS, Ouyang K, Chen J, Dirksen RT, Cheng H. Superoxide flashes in single mitochondria. Cell, 2008, 134: 279-290

3 Fang H, Chen M, Ding Y, Shang W, Xu J, Zhang X, Zhang W, Li K, Xiao Y, Gao F, Shang S, Li JC, Tian XL, Wang SQ, Zhou J,
Weisleder N, Ma J, Ouyang K, Chen J, Wang X, Zheng M, Wang W, Zhang $\mathrm{X}$, Cheng $\mathrm{H}$. Imaging superoxide flash and metabolismcoupled mitochondrial permeability transition in living animals. Cell Res, 2011, 21: 1295-1304

4 Zhang X, Huang Z, Hou T, Xu J, Wang Y, Shang W, Ye T, Cheng H, Gao F, Wang X. Superoxide constitutes a major signal of mitochondrial superoxide flash. Life Sci, 2013, 93: 178-186

5 Hou T, Zhang X, Xu J, Jian C, Huang Z, Ye T, Hu K, Zheng M, Gao F, Wang X, Cheng H. Synergistic triggering of superoxide flashes by mitochondrial $\mathrm{Ca}^{2+}$ uniport and basal reactive oxygen species elevation. J Biol Chem, 2013, 288: 4602-4612

6 Hou Y, Ghosh P, Wan R, Ouyang X, Cheng H, Mattson MP, Cheng A. Permeability transition pore-mediated mitochondrial superoxide flashes mediate an early inhibitory effect of amyloid beta1-42 on neural progenitor cell proliferation. Neurobiol Aging, 2014, 35: 975-989

7 Hou Y, Ouyang X, Wan R, Cheng H, Mattson MP, Cheng A. Mitochondrial superoxide production negatively regulates neural progenitor proliferation and cerebral cortical development. Stem Cells, 2012, 30: 2535-2547

8 Ma Q, Fang H, Shang W, Liu L, Xu Z, Ye T, Wang X, Zheng M, Chen Q, Cheng H. Superoxide flashes: early mitochondrial signals for oxidative stress-induced apoptosis. J Biol Chem, 2011, 286: 27573-27581

9 Cao Y, Zhang X, Shang W, Xu J, Wang X, Hu X, Ao Y, Cheng H. Proinflammatory cytokines stimulate mitochondrial superoxide flashes in articular chondrocytes in vitro and in situ. PLoS ONE, 2013, 8: e66444

10 Shen EZ, Song CQ, Lin Y, Zhang WH, Su PF, Liu WY, Zhang P, Xu J, Lin N, Zhan C, Wang X, Shyr Y, Cheng H, Dong MQ. Mitoflash frequency in early adulthood predicts lifespan in Caenorhabditis elegans. Nature, 2014, doi: 10.1038/nature13012

11 Halestrap AP. What is the mitochondrial permeability transition pore? J Mol Cell Cardiol, 2009, 46: 821-831

12 Li K, Zhang W, Liu J, et al. Flash Sniper: automated detection and analysis of mitochondrial superoxide flash. Biophys J, 2009, 96 : 531a-532a

13 Bernardi P. The permeability transition pore. Control points of a cyclosporin A-sensitive mitochondrial channel involved in cell death. Biochim Biophys Acta, 1996, 1275: 5-9

14 Baughman JM, Perocchi F, Girgis HS, Plovanich M, Belcher-Timme CA, Sancak Y, Bao XR, Strittmatter L, Goldberger O, Bogorad RL, Koteliansky V, Mootha VK. Integrative genomics identifies MCU as an essential component of the mitochondrial calcium uniporter. Nature, 2011, 476: 341-345

15 De Stefani D, Raffaello A, Teardo E, Szabò I, Rizzuto R. A forty-kilodalton protein of the inner membrane is the mitochondrial calcium uniporter. Nature, 2011, 476: 336-340

16 Denton RM, Randle PJ, Bridges BJ, Cooper RH, Kerbey AL, Pask HT, Severson DL, Stansbie D, Whitehouse S. Regulation of mammalian pyruvate dehydrogenase. Mol Cell Biochem, 1975, 9: 27-53

17 Harris DA, Das AM. Control of mitochondrial ATP synthesis in the heart. Biochem J, 1991, 280: 561-573

18 Mildaziene V, Baniene R, Nauciene Z, Bakker BM, Brown GC, Westerhoff HV, Kholodenko BN. Calcium indirectly increases the control exerted by the adenine nucleotide translocator over 2-oxoglutarate oxidation in rat heart mitochondria. Arch Biochem Biophys, 1995, 324: 130-134

19 Al-Nasser I, Crompton M. The reversible $\mathrm{Ca}^{2+}$-induced permeabilization of rat liver mitochondria. Biochem J, 1986, 239: 19-29

20 Crompton M, Costi A, Hayat L. Evidence for the presence of a reversible $\mathrm{Ca}^{2+}$-dependent pore activated by oxidative stress in heart mitochondria. Biochem J, 1987, 245: 915-918

Open Access This article is distributed under the terms of the Creative Commons Attribution License which permits any use, distribution, and reproduction in any medium, provided the original author(s) and source are credited. 